\title{
Dyslexia and Cerebral Dysfunction
}

\section{Theofilidis Antonis}

Cognitive -Clinical Neuropsychologist, 3rd Department of Psychiatry, School of Medicine, Aristotle University of Thessaloniki, Greece.

Corresponding Author: Theofilidis Antonis, Cognitive -Clinical Neuropsychologist, 3rd Department of Psychiatry, School of Medicine, Aristotle University of Thessaloniki, Greece.

\section{Received date: November 02, 2021; Accepted date: November 19, 2021; Published date: January 06, 2022}

Citation: T Antonis. (2022) Dyslexia and cerebral dysfunction. Clinical Research and Clinical Trials. 5(1); DOI: 10.31579/26934779/070

Copyright: (C) 2022 Theofilidis Antonis, This is an open access article distributed under the Creative Commons Attribution License, which permits unrestricted use, distribution, and reproduction in any medium, provided the original work is properly cited.

\begin{abstract}
:
Children with slow visual-motor responses to visual-temporal response tests also have brain dysfunctions in the mobile and motor areas $(6,4)$. If the left parietal cortex does not participate in these dysfunctions, then this child will also have difficulties in reading. Furthermore, we could say that the brain dysfunctions that are detected by visual-motor tests and that the performance in them is low, are accompanied by difficulties in reading.

Aim: In this study we want to show the function of the child's brain in dyslexia.

Method: We followed the most up-to-date literature on the subject: neuropsychology and dyslexia.

Conclusions: brain organization and its relationship to dyslexia is a major problem for Neuropsychology and Neurolinguistics.

Keywords: dyslexia; cerebral dysfunction; neuropeychology
\end{abstract}

\section{Introduction}

Visual ignorance results from lesions of the left occipital parietal cortex as well as lesions of a specific area (splenium) of the medulla oblongata. The result of visual ignorance is the appearance of grammatical dyslexia. That is, it is an inability of the child to individually recognize the letters of the alphabet and to relate their linguistic meanings (Benson and Geschwind, 1969, 9]. The term "lexical blindness" was also used for this type of dyslexia, which means that this patient can see the word but cannot understand it. Visual search and discrimination is disrupted by lesions of the right parietal, occipital, and frontal cortex [9]. Especially if the lateral fields of the frontal lobes are dysfunctional, the perception of depth is significantly disturbed. However, the left hemisphere seems to be responsible for the perception of letters and words.

The right hemisphere seems to be responsible for the perception of shapes and images. It has been found $[7,8]$ that children aged five to six years, when preparing to read a text, activate right hemisphere mechanisms. As children get older, they begin reading by activating left hemisphere mechanisms, and then a hemispherical collaboration is established. Lesions located in the left frontal cortex and left motor field [9] disrupt the perception of visual followers. It has also been found [4] that people with brain damage in the temporal visual-motor response tests perform significantly lower than normal, especially if the brain damage is to the motor fields on the opposite side of the hand. In fact, this hand had a very low performance. It is a fact, however, that children who have slow visualmotor reactions to visual-motor temporal response tests also have brain dysfunctions in the motor and motor areas $(6,4)$. If the left parietal cortex is not involved in these dysfunctions, then this child will also have difficulty reading. Furthermore, we could say that chronic brain dysfunctions that are detected by visual-motor reaction tests and that the performance in them is low, are accompanied by difficulties in reading. From the above findings, there seems to be some responsibility of opticomotor neural communications in reading processes.

If a child has a hearing impairment, there may be damage or dysfunction peripherally (hearing system, ear, labyrinth, cochlea, up to the middle knee body in the chamber) or central dysfunction with central deafness and damage or dysfunction to located in the left hemisphere in the Wernicke field or Heschl helix. Also, if a child perceives clear tones or words, which means that Heschl's helix works normally, but he cannot distinguish words such as, for example, "good" and "bad" or "rose" and "pomegranate" etc. when he hears them, it shows a fault or malfunction in the Wernicke area. These neuropsychological [9] had distinguished and described the differences in a remarkable way and valid. He had even argued that local damage to the secondary area of the left temporal cortex (Wernicke field) in the child have as consequently the difficulty of distinguishing speech sounds. This difficulty is the beginning for receptive aphasia. Damage to the cortex is the main cause factor for aesthetic or receptive aphasia. Reading is needed decoding mechanisms from the visual and auditory 
system. Any form of receptive aphasia (meaning impaired understanding of words) has as a consequence reading disorders.

Usually Wernicke's childhood aphasia shows the same difficulties in reading as in auditory comprehension. Acoustic memory is disturbed by lesions of the left temporal lobe [9] and by electrical stimuli - especially short-term lingual memory - in the frontal-parietal-temporal areas of the left hemisphere (Ojemann, 1983). Dysfunctions in the left hemisphere and in the temporal, parietal, and occipital areas cause disturbances in auditorylinguistic comprehension [13].

In addition to the visual-kinetic temporal response tests and their importance in understanding reading mechanisms, there are also acoustickinetic temporal response tests. Usually, in trials of the reaction time six (6) different ones are used sensory-motor combinations. These are the following:

1) Right ear right hand, 2) right ear -> left hand, 3) Left ear -> right

hand, 4) Left ear-> left hand, 5) Both ears right hand and, 6)

Both ears left hand. Feet can also be used. In this test we ask the child to press a button or something else with his right or left hand after a stimulussound (tone) that will be received in his left or right ear. The average response time in adults in this test is $75 \mathrm{~ms}$ that is, the reaction time is shorter compared to that of the optico-motor test which is around $125 \mathrm{~ms}$. This is because the auditory-cortical-motor communications are shorter than the visual-motor ones. From the ear the stimulus goes to the temporal cortex. Audio-motor communications are about half or less of visual-motor communications. These tests are valuable tools for studying reading difficulties and we believe that in the future there will be a lot of research. However, their role in the diagnosis of brain function seems to be remarkable. This is shown by the fact that a right-handed person with a predominance of language in the left hemisphere and normal hearing should have faster temporal reactions to combinations one (1) and five (5). But if this does not happen, then such a person should suffer from damage or dysfunction in the left hemisphere and thus cause reading difficulty. The role of tactile learning in reading seems to be quite important and primary [14, Phillips, 1975). We measure the tactile-kinetic functions with the tactile meter. Usually a tactile or motor difficulty in one hand means damage or malfunction in the opposite hemisphere of the hand and in the tactile or motor fields.

A difficulty, e.g. of the right hand is usually accompanied by reading disorders as both of these functions are controlled by specific areas of the left parietal lobe. It is also worth noting the role of stereotyping mechanisms in reading functions. This has been found with therapeutic neuropsychological programs [1] that seek to activate and improve dysfunction by causing specific neurotherapeutic stimuli. According to clinical neuropsychological studies [5], there is a relationship between reading difficulties and impaired recognition of tactile localization of the fingers of both hands. But most of all, the disturbance of the tactile perception of locating the stimulus concerns the fingers of the right hand. This is because the reading and tactile local recognition of the fingers are performed by mechanisms of the left parietal cortex, so their dysfunctions affect both skills. The degree of grip strength with the hands and the functions of the reading seem to have something to do. This is because cellular communications. Involved in language functions, if they malfunction together with other structures of the brainstem, disrupt reading. The grip strength with the hands is controlled by structures of the brain stem and the malfunctions located in the brain stem reduce the dynamic grip performance of the hands. It is also known [11] that electrostimulation of the left ventricle causes difficulties in naming objects, arithmetic and linguistic recall. Future research will hopefully show more about the role of the hand grip and its relationship to the brain's reading mechanisms. The child with expression aphasia has difficulty reading. Usually the child with developmental aphasia has severe joint problems and disorders in their otomotor system [10] It seems that for the linguistic development of the child, while at the beginning of his life the receptiveperceptual language analysis plays an important role, after about the fifth year of his school life, ie around the age of eleven (11) years, the expressive-kinetic mechanisms of language prevail more in its linguistic behavior.

Bilateral brain damage in the parietal cortex, and especially in the thirtynine field (39), causes reading disturbances. But apart from that, there is a disturbance in the orientation mechanisms to the right or left. Thus, many times, children with reading difficulties also show problems of orientation to the right or left, up or down in their space. Hand preference, brain organization and their relationship to dyslexia are significant problems for Neuropsychology and Neurolinguistics [6]. There is a controversy between his preference hand, brain organization and their relationship to dyslexia. When there is left-handedness, but usually not always, there is also difficulty reading. In the left hand, however, the predominance of the tongue may be in the left hemisphere, or very rarely in the right or both. Also about what happens in the left hand and its relationship with many disorders such as e.g. dyslexia or with special abilities such as e.g. superior intelligence, much more research needs to be done. The ability of the audiovisual sequence and the relationship with reading has been studied by the Bakker team in Amsterdam.

In a remarkable study [2] in children aged 6-8 years he distinguished four (4) types of behavioral sequence: a) linguistic imitation (receptive or perceptual), b) non-linguistic imitation c) linguistic expression and, d) nonverbal expression. Examined the time sequences in the four categories and the three channels (optical-acoustic-tactile). He found that the chronological sequence was age-related and that girls between the ages of 6 and 7 were superior to boys. Between 7 and 8 , the girls were equivalent in recalling tests with sequences for all three aesthetic channels. From the 8th to the 11th year the tactile capacity is reduced and emphasis is placed on audiovisual sequence skills. The girls seemed superior in recalling chronicles sequences for all aesthetic channels and after the age of 9 years. The boys' performance was without particular inconsistencies and instabilities. The conclusion from this research is that the temporal perception of linguistic material and linguistic coded material, performed by the hemisphere of the language, that is, the left. A recent study [14] found low performance in verbal-memory tests in both P- and L-dyslexic types. L-types also performed poorly in image rotation tests. This means that this guy has a visual-motor disorder in reading of difficulty. Parents of $\mathrm{P}$ - and L-dyslexic types had low performance in verbal-memory tests. They showed no visual-spatial disturbances trials. In families with P-dyslexic types, a substantial one was found relationship between father and son for visual-spatial functions. In families with L- dyslexic types, parent-child relationships for both parents but also for the two categories (verbalmnemonic and visual-spatial) were weaker.

\section{References}

1. Ayres A J. (1975). Sensorimotor foundations of academic ability. In Cruick shank, W.M. and Hallahan, D.P. (Eds): Perce3ptual and learning disabilities in children. Syracuse, University Press. 2:300-385.

2. Bakker D.J, Van der Vlugt. (1989). Learning disabilities. Swets and Zeitlinger.

3. Bakker D.J. (1972). Temporal order in disturbed reading. Rotterdam, University Press.

4. Benton AL, Blackburn H.L. (1957). Practice effects in reaction time tasks in brain-injured patients. Journal of Abnormal and Social Psychology. 1:109-113.

5. Gaddes WH. (1985). Learning disabilities and brain function, Springer- Verlag, New York.

6. Hecaen H. (1984). Les gauchers, Ed. P.U.F, Paris. 
7. Holmes M.B. (1982). In Malatesha, R.N. and Aaron, RG (Eds): Reading disorders: Varieties and Treatments. New York, Acad. Press.

8. Licht R et al. (1988). The development of lateral event-related Potentials (ERPs) related to word naming: A four year longitudinal study Neuropsychologia. 26(2):327-340.

9. Luria A. (1973). The working brain. Harmondsworth, Penguin Books.

10. Mattis S. et al. (1975). Dyslexia in Children and young adults: three independent neyropsychological syndromes. De velopmental Medicine and Child Neurology. 17:150-163.
11. Ojemann G. A. (1975). Language and the thalamus: Object naming and recall during and after thalamic stimulation. Brain and Language. 2:101-120.

12. Ojemann GA. (1983). Interrelationships in the brain organization of language-related behaviors: Evidence from ical stimulation mapping In Kirk, U. (Eds): Neuropsychology of language, reading and spelling. New York, Academic Press. 50:164-169.

13. Piaget J, Inhelder B. (1956). The child's conception of space. London: Routledge and Kegan Paul.

14. Van Strien J.W et al. (1990). Familial Resemblance for cognitive Abilities Families with Ptype dyslexic, L-type dyslexic or normal reading boys. Journal of Clinical and Experimen-tal Neuropsycholoy. 12(6):843-857.
This work is licensed under Creative Commons Attribution 4.0 License

To Submit Your Article Click Here:

DOI: $10.31579 / 2693-4779 / 070$
Ready to submit your research? Choose Auctores and benefit from:

$>$ fast, convenient online submission

$>$ rigorous peer review by experienced research in your field

$>$ rapid publication on acceptance

$>$ authors retain copyrights

$>$ unique DOI for all articles

$>$ immediate, unrestricted online access

At Auctores, research is always in progress.

Learn more https://auctoresonline.org/journals/clinical-research-and-clinicaltrials 